\title{
AVALIAÇÃO DA APLICAÇÃO DO ENSAIO DE TRAÇÃO A QUENTE (INSTRON) PARA A DETERMINAÇÃO DE CUUVAS TENSÃO-DEFORMAÇÃO DO AÇO 22MNB5 ÀS TEMPERATURAS DE ESTAMPAGEM A QUENTE *
}

\author{
Fernanda Mitke Maria de Lacerda Rocha Hoppe Rocha ${ }^{1}$ \\ Augusto Cesar Almeida de Oliveira ${ }^{2}$ \\ Antônio José de Oliveira Cabra/ ${ }^{3}$ \\ Alexandre Pimentel Sampaio ${ }^{4}$
}

\section{Resumo}

O objetivo deste trabalho foi avaliar a capacidade da máquina de tração Instron em conjunto com um forno acoplado em sua estrutura (especialmente desenvolvido para este fim) para a obtenção das curvas tensão versus deformação do aço 22MnB5 nas temperaturas usualmente empregadas no processo de estampagem a quente. Adicionalmente, teve como objetivo avaliar a influência da temperatura nas propriedades mecânicas do aço para estampagem a quente. De posse dos dados experimentais de tensão e deformação foram realizadas tentativas de ajuste aos modelos constitutivos Voce-Kocks e Hollomon para as diferentes temperaturas. Os resultados demonstraram que o conjunto Instron-forno foi capaz de entregar resultados com repetibilidade, permitindo assim o ajuste dos dados ao modelo de Voce-Kocks na maior parte dos casos.

Palavras-chave: Tração a quente, Instron, Aço 22MnB5, Relações constitutivas, Estampagem a quente.

\section{EVALUATION OF THE APPLICATION OF THE HOT TENSILE TEST (INSTRON) FOR THE DETERMINATION OF STRESS-STRAIN CURVES OF 22MNB5 STEEL AT HOT STAMPING TEMPERATURES}

\section{Abstract}

The goal of this work was to evaluate the feasibility of an Instron tensile test machine in conjunction with a special designed resistance furnace placed on its structure to acquire the stress-strain curves of the 22MnB5 steel in those temperatures usually employed in the hot stamping process. In addition, it was also evaluated the influence of the temperature on the mechanical properties of the boron steel. Attempts were also made to fit the experimental data with the constitutive models proposed by Voce-Kocks and Hollomon for the different temperatures. The results showed that the proposed solution (Instron and resistance furnace) could for the most cases deliver results with repeatability, allowing the fitting process of the experimental data per the Voce-Kocks model.

Keywords: Hot tensile test, Instron, 22MnB5 steel, Constitutive models, Hot stamping.

1 Engenheira Metalúrgica, Mestranda, Departamento de Engenharia Mecânica, Universidade Federal Fluminense, Volta Redonda, Rio de Janeiro, Brasil.

2 Engenheiro Metalúrgico, D.Sc, Professor Adjunto, Departamento de Engenharia Metalúrgica, Universidade Federal Fluminense, Volta Redonda, Rio de Janeiro, Brasil.

3 Engenheiro Mecânico, D.Sc, Professor Associado, Departamento de Engenharia Mecânica, Universidade Federal Fluminense, Volta Redonda, Rio de Janeiro, Brasil.

4 Engenheiro Metalúrgico, M.Sc, Gerente de Garantia da Qualidade, Companhia Siderúrgica Nacional, Volta Redonda, Rio de Janeiro, Brasil. 


\section{INTRODUÇÃO}

Focado no constante desenvolvimento tecnológico e na necessidade de reduzir o peso dos veículos, devido à necessidade de redução de queima de combustível e emissão de poluentes, e, ao mesmo tempo, aumentar os níveis de segurança dos passageiros, tem-se buscado novas soluções no desenvolvimento de componentes eficazes na produção de veículos. Nesse contexto surgiram os aços PHS (Press Hardened Steels). Porém esses aços não são facilmente conformados, surgindo assim a necessidade de realização do processo de estampagem a altas temperaturas seguido de têmpera para a obtenção das propriedades mecânicas necessárias. Este processo é chamado de endurecimento na prensa (press hardening) ou estampagem a quente (hot stamping). (GORNI, 2010; NADERI, 2007a)

Para compreender melhor as variáveis envolvidas no processo de estampagem a quente surgiu a necessidade de obter informações sobre o comportamento mecânico dos materiais usados para esse fim quando submetidos a deformações em altas temperaturas. A caracterização experimental desses materiais em diferentes temperaturas e taxas de deformação é necessária, porém leva tempo e tem alto custo. A modelagem constitutiva é particularmente útil para a simulação numérica de aplicações industriais. (NADERI et. al, 2008a)

O ensaio de tração a temperaturas elevadas é de grande utilidade para estimar a capacidade dos metais de suportar forças de tração aplicadas. Com o auxílio de relações convencionais já estabelecidas, pode-se utilizar os resultados desse ensaio para indicar o provável comportamento dos metais sobre outros estados simples de tensão, como compressão e cisalhamento por exemplo. Com o auxílio de modelos, informações importantes sobre o comportamento dos metais podem ser obtidas através dos resultados do ensaio de tração a quente.

Este trabalho avaliou a capacidade de realização e obtenção de resultados consistentes do conjunto "Máquina Instron de tração e forno especialmente desenvolvido por aquecimento resistivo" para a obtenção de curvas tensão versus deformação em temperaturas elevadas, o comportamento plástico do aço 22MnB5 durante o ensaio de tração realizado a altas temperaturas por meio da comparação entre as propriedades mecânicas e microestruturas obtidas e 0 ajuste dos dados experimentais às relações constitutivas propostas por Voce, em combinação com o modelo cinético proposto por Kocks, e a equação de Hollomon. Os resultados extraídos do ensaio de tração a temperaturas elevadas foram utilizados para estudar a influência da temperatura na curva tensão versus deformação verdadeira nos aços 22MnB5, e as curvas tensão-deformação foram ajustadas pela aplicação das duas relações constitutivas.

\subsection{O PROCESSO DE ESTAMPAGEM A QUENTE}

O aumento da resistência mecânica das chapas permite a redução de sua espessura sem perda de desempenho mecânico, mas esse aumento de resistência vem acompanhado da diminuição da estampabilidade desses aços. Para lidar com as dificuldades na estampagem tradicional desses aços de alta resistência, foi desenvolvido o processo de estampagem em altas temperaturas, que permite redução das forças aplicadas durante a conformação e melhora a precisão dimensional dos componentes estampados. As principais vantagens da estampagem a quente são a excelente precisão dimensional dos componentes e a 
possibilidade de produzir peças de ultra alta resistência, sem qualquer retorno elástico. (NADERI, 2007a)

O processo de estampagem a quente começa com o aquecimento da chapa até a temperatura de austenitização e em seguida sua transferência do forno para a prensa. Para finalizar, a chapa é conformada dentro da prensa e resfriada por aproximadamente 10 segundos. Essa taxa de resfriamento promove uma têmpera na chapa, fornecendo uma microestrutura final totalmente martensítica devido às altas taxas de resfriamento, da ordem de 50 a $70^{\circ} \mathrm{C} / \mathrm{s}$. O ciclo térmico e as mudanças microestruturais são relacionadas com as propriedades mecânicas na Figura 1. (NADERI, 2007a; ALTAN, 2006)

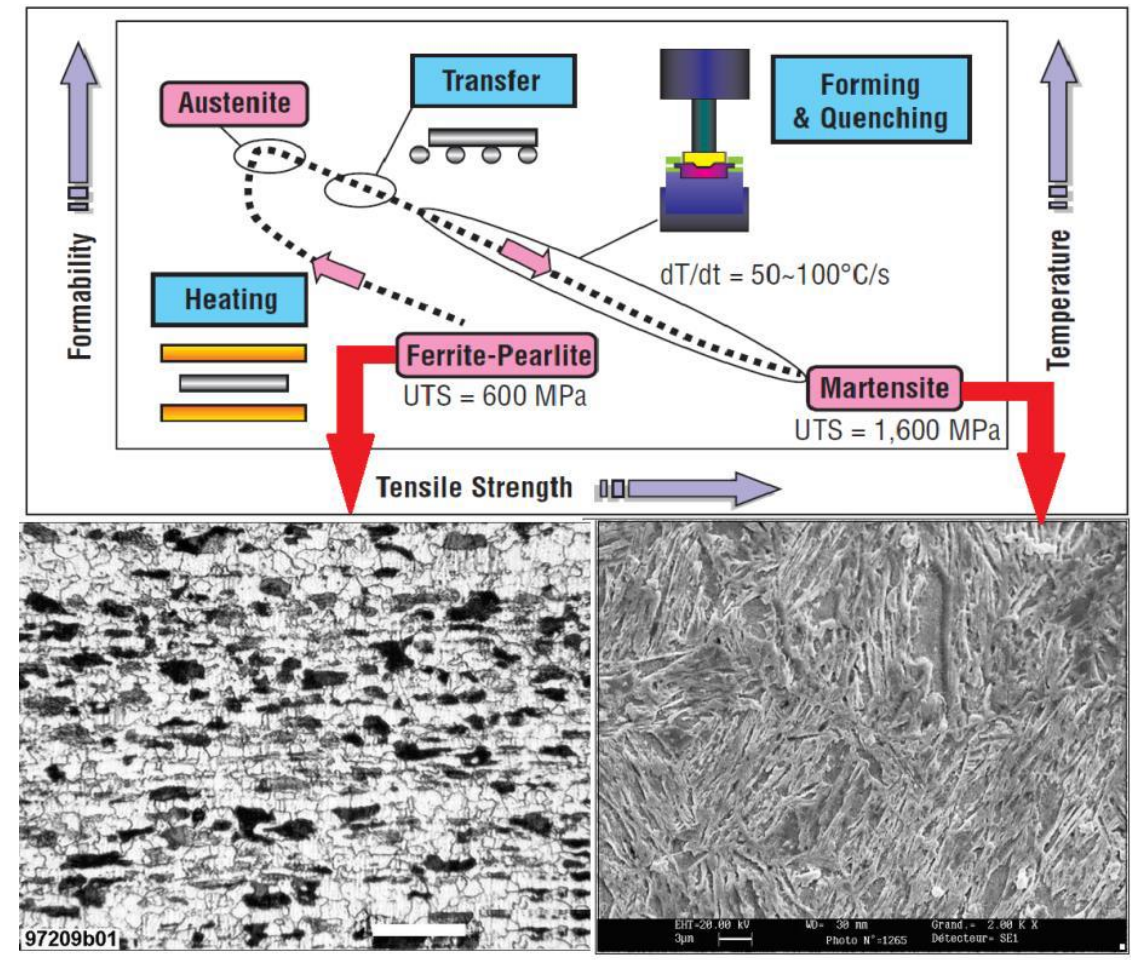

Figura 1. Resistência máxima e mudanças na microestrutura durante a estampagem a quente.

\subsection{AÇOS AO BORO PARA ESTAMPAGEM A QUENTE}

De acordo com Ferrer (2003) apud Giralt (1999), a indústria automotiva é certamente um dos setores que mais exigem melhorias contínuas das propriedades dos aços empregados em seus processos produtivos. A redução do peso dos veículos tem sido o principal objetivo do setor, de modo a reduzir o consumo de combustível e, consequentemente, a emissão de gases que contribuem ao chamado efeito estufa. Há também preocupações constantes com segurança e resistência a impactos.

Os aços ao boro para conformação a quente permitem reduzir a espessura e produzir peças com formas complexas, e são fabricados de acordo com a norma alemã DIN EN 10083-3. O aço ao boro mais utilizado é o 22MnB5, que apresenta microestrutura ferrítico-perlítica com uma dureza de $\sim 171 \mathrm{HV} 10$, limite de escoamento de $400 \mathrm{MPa}$ e limite de resistência de aproximadamente $600 \mathrm{MPa}$, no estado inicial, antes da estampagem a quente.

\subsubsection{INFLUÊNCIA DOS PRINCIPAIS ELEMENTOS DE LIGA}


Segundo Naderi (2007) alguns elementos de liga tem efeito na temperabilidade dos aços. O carbono é o principal elemento de endurecimento em aços mas o aumento do seu teor vem acompanhado da diminuição da ductilidade e da soldabilidade do material. O boro é usado em teores de 0,003 a $0,005 \%$ com o objetivo de aumentar a temperabilidade. $\mathrm{O}$ efeito do boro na temperabilidade é atribuído, em geral, à sua segregação no contorno de grão austenítico, reduzindo a sua energia livre e evitando a nucleação de ferrita. Já o manganês aumenta a temperabilidade e reduz a temperatura de austenitização.

\subsubsection{TRANSFORMAÇÕES MICROESTRUTURAIS NO AÇO 22MnB5}

Em relação à transformação martensítica no aço ao boro deformado, Naderi e Bleck (2007a) realizaram estudos sobre o efeito dos parâmetros do processo de estampagem a quente na temperatura de início (Ms) e na temperatura de final (Mf) da transformação martensítica. A Ms diminui com o aumento do tempo de encharque na temperatura de austenitização devido a grãos mais grosseiros. Quando a deformação a quente é aplicada à austenita, o Ms pode ser diminuído em $40^{\circ} \mathrm{C}$ e o Mf pode ser aumentado em $50^{\circ} \mathrm{C}$. De acordo com Hsu (1999), o Ms será diminuído para um certo nível devido ao endurecimento de austenita e sua estabilização mecânica. A Ms tem uma relação linear com deformação da austenita. Esse fenômeno é encontrado nos aços ao boro independentemente de a deformação ser isotérmica ou não-isotérmica. (NADERI e BLECK, 2007a; NADERI e SAEED-A, 2008)

Quanto às taxas de resfriamento, sua influência sobre as transformações de fase pode ser vista a partir do diagrama de transformação não-isotérmica, Figura 2, que mostra que para se obter uma microestrutura totalmente martensítica é necessário uma taxa de resfriamento igual ou superior a $25^{\circ} \mathrm{C} / \mathrm{s}$. (NADERI et. al, 2008b)

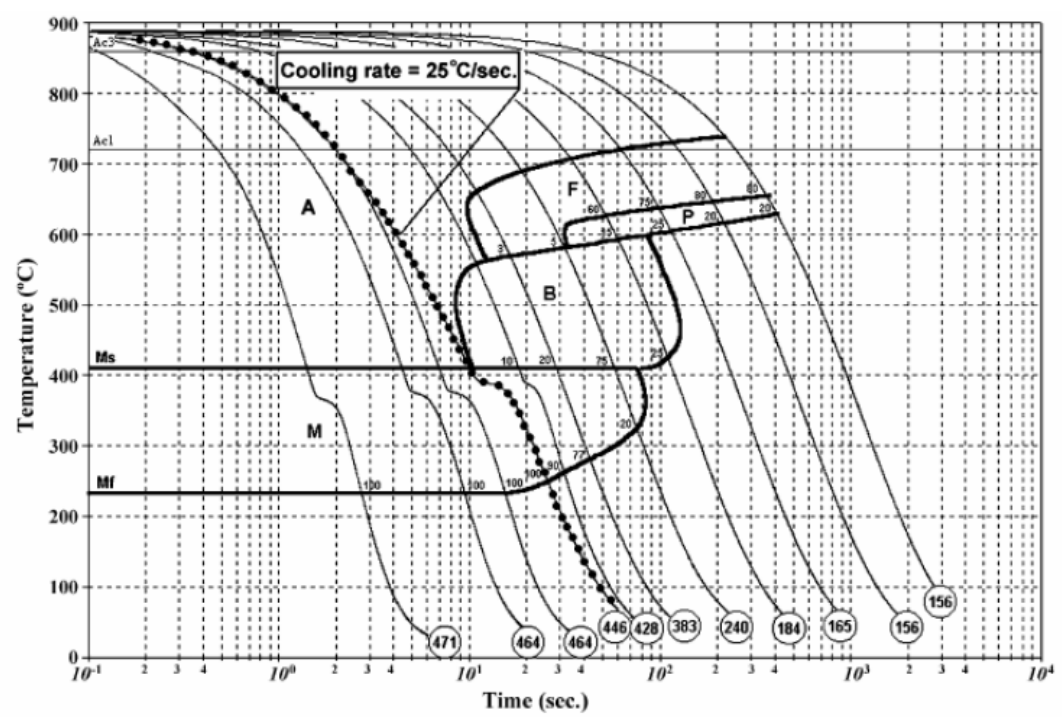

Figura 2. Diagrama de transformação anisotérmica para o aço ao boro $22 \mathrm{MnB5}$ (aco hipoeutectoide). Exemplo para um período de austenitizacao a $900^{\circ} \mathrm{C}$ durante 5 minutos.

\subsection{RELAÇÕES CONSTITUTIVAS}

Comum a todas as análises mecânicas de materiais de engenharia, o comportamento em componentes estruturais é a necessidade de modelos constitutivos que ligam os estados de tensão e deformação. Do ponto de vista 
matemático, as equações constitutivas (que definem o modelo constitutivo) são equações complementares ao equilíbrio e às equações cinemáticas. As abordagens conceitualmente diferentes para a derivação de modelos constitutivos macroscópicos são: fenomenológica, baseada na aplicação de princípios fundamentais, empírica, baseada em dados experimentais, desconhecendo-se totalmente os mecanismos de causa/efeito entre as variáveis dependentes. (FRÖBERG, 1965)

\subsubsection{MODELO DE VOCE-KOCKS}

Na sua versão original, o modelo de Voce refere-se a três parâmetros; a tensão de escoamento inicial, a tensão máxima e a deformação de relaxação, e não é função da velocidade de deformação e nem da temperatura. Para descrever a influência dessas variáveis, o modelo cinético proposto por Kocks é introduzido na formulação de Voce para descrever a dependência da taxa de deformação e da temperatura no limite de escoamento e na tensão e de saturação. (NADERI et. al, 2008a)

A equação de Voce é mais adequada quando a tensão de saturação ocorre mediante grandes deformações. A tensão de saturação, nesse modelo, corresponde ao final da deformação uniaxial mostrada por materiais policristalinos antes da estricção. O modelo constitutivo proposto por Voce é definido pela Equação 1:

$$
\sigma=\sigma_{\mathrm{s}}+\left[\left(\sigma_{0}-\sigma_{\mathrm{s}}\right) \exp \left(-\frac{\varepsilon}{\varepsilon \mathrm{r}}\right)\right]
$$

onde $\sigma_{s}$ é o valor da tensão de saturação, $\sigma_{0}$ o limite de escoamento inicial e $\varepsilon r$ representa a deformação de relaxação. A tensão de relaxação determina a taxa na qual a tensão tende a seus valores de estado estacionário. A Figura 3 ilustra os parâmetros do modelo de Voce. (NADERI et. al, 2008a)

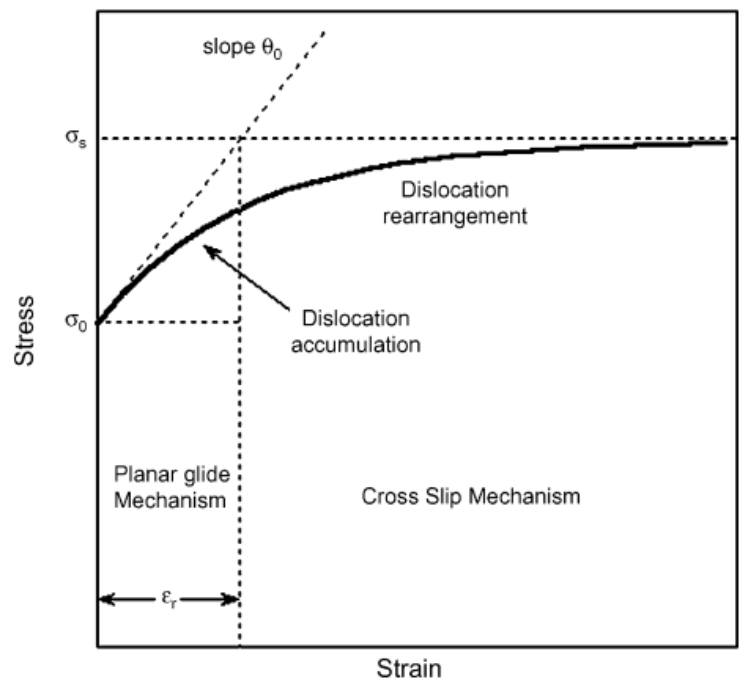

Figura 3. llustração dos parâmetros de VOCE e dos mecanismos de deformação.

A formulação inicial do modelo de Voce é insensível à temperatura e à velocidade de deformação. Kocks propôs uma descrição da tensão de saturação como uma função da temperatura e da taxa de deformação. A relação de dependência da tensão de saturação em relação a temperatura e da taxa de deformação é dada na Equação 2: 


$$
\sigma_{S}=\sigma_{S 0} \frac{\varepsilon^{\cdot(\mathrm{kT} / \mathrm{As})}}{\varepsilon^{\prime} \mathrm{s} 0}
$$

onde $A s=\mu b^{3}$, k representa a constante de Boltzmann, $\mu$ o módulo de cisalhamento dependente da temperatura, b o vetor de Burgers e $\varepsilon^{\prime}$ so, A e $\sigma$ so são parâmetros do material que podem ser determinados experimentalmente. A tensão de referência $\sigma_{\text {so }}$ é a tensão do limiar de saturação em zero Kelvin. Nota-se então que a dependência de $\varepsilon r$ em relação à temperatura não apresenta tendências claras. No entanto, $\varepsilon r$ é claramente uma função decrescente da taxa de deformação que pode ser representada pela seguinte lei de potência em que C1, C2 são parâmetros de material e $\varepsilon^{\circ} 0$ é uma taxa de deformação de referência (Equação 3). (NADERI et. al, 2008a)

$$
\varepsilon r=C 1 \times\left(\varepsilon_{0}^{*} / \varepsilon^{*}\right){ }^{C 2}
$$

\subsubsection{MODELO DE HOLLOMON}

As equações mais utilizadas para ajustar as curvas tensão vs. deformação em casos onde a tensão aumenta monotonicamente são as de Hollomon, Ludwig e Swift. A equação de Hollomon (Equação 4) normalmente descreve curvas que apresentam um único estágio de encruamento em um gráfico logarítmico cujo traço é uma reta, onde $\mathrm{K}$ representa um coeficiente de resistência enquanto $\mathrm{n}$ é o expoente de encruamento. (HOLLOMON,1945)

$$
\sigma=\mathrm{Ke}^{\mathrm{n}}
$$

\section{MATERIAIS E MÉTODOS}

\subsection{MATERIAIS ENSAIADOS}

A fim de atender o estudo, foi analisada uma amostra plana laminada a quente com 3,6 $\mathrm{mm}$ de espessura cuja composição química foi determinada via espectrometria ótica com o uso do equipamento Óptico ARL conforme apresentado na Tabela 1. $O$ teor dos elementos analisados estava de acordo com a norma DIN EN 10083, comprovando assim a natureza do material analisado.

Tabela 1. Composição química da amostra plana analisada em porcentagem de peso

\begin{tabular}{cccccccccc}
\hline $\mathbf{C}$ & $\mathbf{M n}$ & $\mathbf{S i}$ & $\mathbf{A l}$ & $\mathbf{T i}$ & $\mathbf{C r}$ & $\mathbf{B}$ & $\mathbf{M o}$ & $\mathbf{C u}$ & $\mathbf{N i}$ \\
\hline 0,25 & 1,143 & 0,208 & 0,046 & 0,05 & 0,156 & 0,0031 & 0,008 & 0,011 & 0,007 \\
\hline
\end{tabular}

Para a realização dos ensaios de tração, dez corpos de prova foram retirados na direção transversal à direção de laminação. As dimensões dos corpos de prova foram definidas conforme a norma ASTM E8/E8M e estão representada na Figura 4.

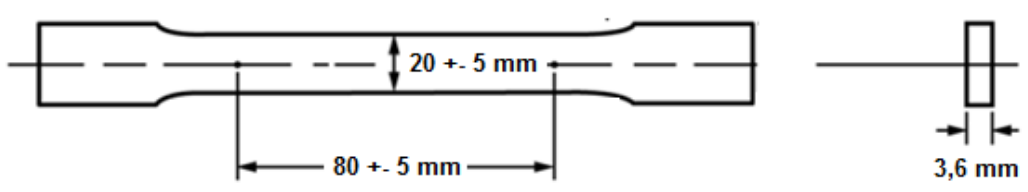

Figura 4. Corpo de prova utilizados para ensaios de tração. 


\subsection{ENSAIO DE TRAÇÃO A QUENTE}

Os ensaios foram executados conforme a norma ASTM E 21 - 09 em uma máquina Instron 4206 com capacidade de carga de 15T (15000kgf). Para aquecimento do corpo de prova, foi acoplado a máquina de tração um forno elétrico com capacidade de aquecimento até $1000^{\circ} \mathrm{C}$. O controle de temperatura no corpo de prova foi medido através de um termopar de contato. A Figura 5 mostra o posicionamento dos termopares, do forno e do corpo de prova dentro do forno.

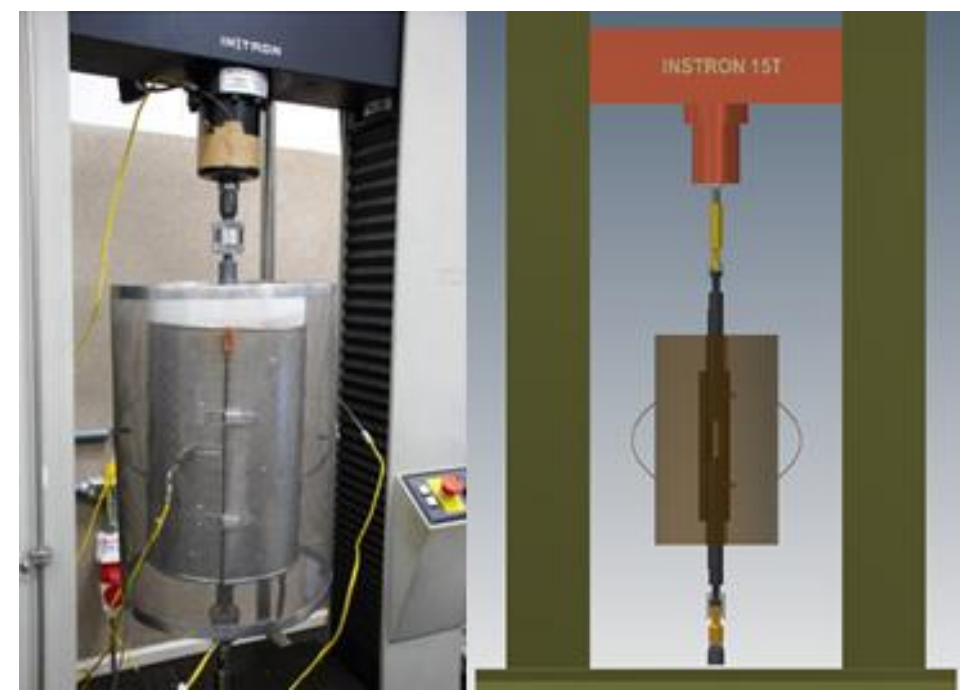

Figura 5. Posicionamento do forno acoplado a máquina de ensaios, dos termopares e do CP dentro do forno durante o ensaio de tração.

Os ensaios foram realizados conforme ASTM E 21 - 09 em corpos de prova de base de medida de $80 \mathrm{~mm}$ conforme os parâmetros da Tabela 2.

Tabela 2. Parâmetros do ensaio de tração uniaxial

\begin{tabular}{cccc}
\hline Máquina & Escala & Extensômetro & Vel. ensaio até LE: \\
\hline INSTRON 15T & $15.000 \mathrm{Kgf}$ & 80 & $50 \mathrm{~mm} / \mathrm{min}$
\end{tabular}

Foram ensaiados 9 corpos de prova, sendo três para cada temperatura, 650, 750 e $900^{\circ} \mathrm{C}$ respectivamente. A taxa de deformação foi de $0,05 \mathrm{~s}^{-1}$ e se manteve constante para todos os ensaios. Os corpos de prova foram aquecidos até a temperatura de $900^{\circ} \mathrm{C}$ e mantidos nessa temperatura por 5 minutos, para homogeneização e austenitização completa.

Os corpos de prova ensaiados a $900^{\circ} \mathrm{C}$, foram ensaiados logo após o tempo de encharque e em seguida retirados do forno e resfriados ao ar. Os corpos de prova ensaiados a 650 e $750^{\circ} \mathrm{C}$ foram submetidos a um resfriamento dentro do forno, logo após o tempo de encharque até a temperatura de ensaio. Atingida essa temperatura, permaneceram mais 5 minutos no forno para homogeneização e em seguida foram tracionados. Após o rompimento, os corpos de prova foram retirados do forno e resfriados ao ar. Todos os ensaios foram realizados à temperatura constante sob controle do sistema automático do forno. A taxa de aquecimento média do forno é de $10,4^{\circ} \mathrm{C} / \mathrm{min}$ e a taxa de resfriamento média é de $6,97^{\circ} \mathrm{C} / \mathrm{min}$. O tempo de encharque para homogeneização da temperatura antes do início da aplicação da carga também foi de cinco minutos. 


\section{RESULTADOS E DISCUSSÃO}

\subsection{PROPRIEDADES MECÂNICAS}

Os resultados obtidos nos ensaios de tração são apresentados na Tabela 3. Um corpo de prova foi ensaiado à temperatura ambiente para efeito de comparação com os resultados dos corpos de prova ensaiados a altas temperaturas. Pode-se observar que o aumento da temperatura provoca redução no limite de escoamento e na tensão máxima suportada pelos corpos de prova. Os corpos de prova que apresentaram maior alongamento foram os ensaiados a $750^{\circ} \mathrm{C}$.

Tabela 3. Propriedades mecânicas

\begin{tabular}{ccccc}
\hline C.P. & ALONG. $(\mathbf{m m})$ & ALONG. \% & LE. 0,2\% (MPa) & T.MÁX. (MPa \\
\hline $\mathrm{CP} 1-25^{\circ} \mathrm{C}$ & 103 & 30 & 531 & 710 \\
\hline $\mathrm{CP} 2-900^{\circ} \mathrm{C}$ & 103 & 29 & 70 & 83 \\
\hline $\mathrm{CP} 3-900^{\circ} \mathrm{C}$ & 103 & 29 & 74 & 85 \\
\hline $\mathrm{CP} 4-900^{\circ} \mathrm{C}$ & 102 & 27 & 66 & 82 \\
\hline $\mathrm{CP} 5-750^{\circ} \mathrm{C}$ & 125 & 56 & 90 & 130 \\
\hline $\mathrm{CP} 6-750^{\circ} \mathrm{C}$ & 123 & 54 & 90 & 128 \\
\hline $\mathrm{CP} 7-750^{\circ} \mathrm{C}$ & 125 & 57 & 93 & 131 \\
\hline $\mathrm{CP} 8-650^{\circ} \mathrm{C}$ & 111 & 39 & 125 & 180 \\
\hline $\mathrm{CP} 9-650^{\circ} \mathrm{C}$ & 114 & 42 & 154 & 191 \\
\hline $\mathrm{CP} 10-650^{\circ} \mathrm{C}$ & 114 & 40 & 124 & 187 \\
\hline
\end{tabular}

É importante notar que o resultado do alongamento dos corpos de prova ensaiados a $900^{\circ} \mathrm{C}$ apresentaram valores abaixo do esperado para materiais deformados a quente, onde a ductilidade aumenta com a temperatura. Além disso, a austenita possui estrutura cristalina CFC e por este motivo apresenta um maior número de planos de deslizamento, o que em teoria favorece o alongamento. Várias hipóteses podem justificar o menor alongamento, sendo a mais plausível a impossibilidade do alongamento total ser incapaz de demonstrar um comportamento correlato com a temperatura em função da instabilidade plástica que ocorre no empescoçamento do corpo de prova.

\subsection{METALOGRAFIA}

Foram realizadas análises metalográficas em amostras retiradas próximas à região onde ocorreu a fratura dos corpos de prova a fim de verificar a microestrutura presente resultante dos ciclos térmicos combinados com as deformações as quais os corpos de prova foram submetidos. Verifica-se na matriz a presença de perlita, ferrita e ferrita de Widmanstätten, além de ilhas de bainita nas amostras ensaiadas a $900^{\circ} \mathrm{C}$.

Nos corpos de prova ensaiados a $750^{\circ} \mathrm{C}$, verificou-se a presença de perlita e ferrita. A presença de ferrita foi bem mais acentuada que na amostra ensaiada à temperatura ambiente. Pôde ser notada também a presença de perlita globular e de possível bainita. Também foi observado um crescimento assimétrico dos grãos na amostra ensaiada a $750^{\circ} \mathrm{C}$, pois todos os corpos de prova apresentaram grãos muito maiores que os outros dispersos na matriz. A exemplo do comportamento mecânico, ou em razão deste fato, o comportamento microestrutural também exibiu repetibilidade. 
Nos corpos de prova ensaiados a $650^{\circ} \mathrm{C}$, verificou-se a presença de perlita e ferrita na matriz. Ainda, pôde ser observado um crescimento nos grãos. Isso se deveu ao tempo de permanência no forno, sendo esse grupo o que permaneceu por mais tempo enfornado, devido ao resfriamento necessário para atingir a temperatura de ensaio. Assim como na amostra ensaiada a temperatura ambiente, pode-se observar o alongamento dos grãos no sentido de aplicação da força.
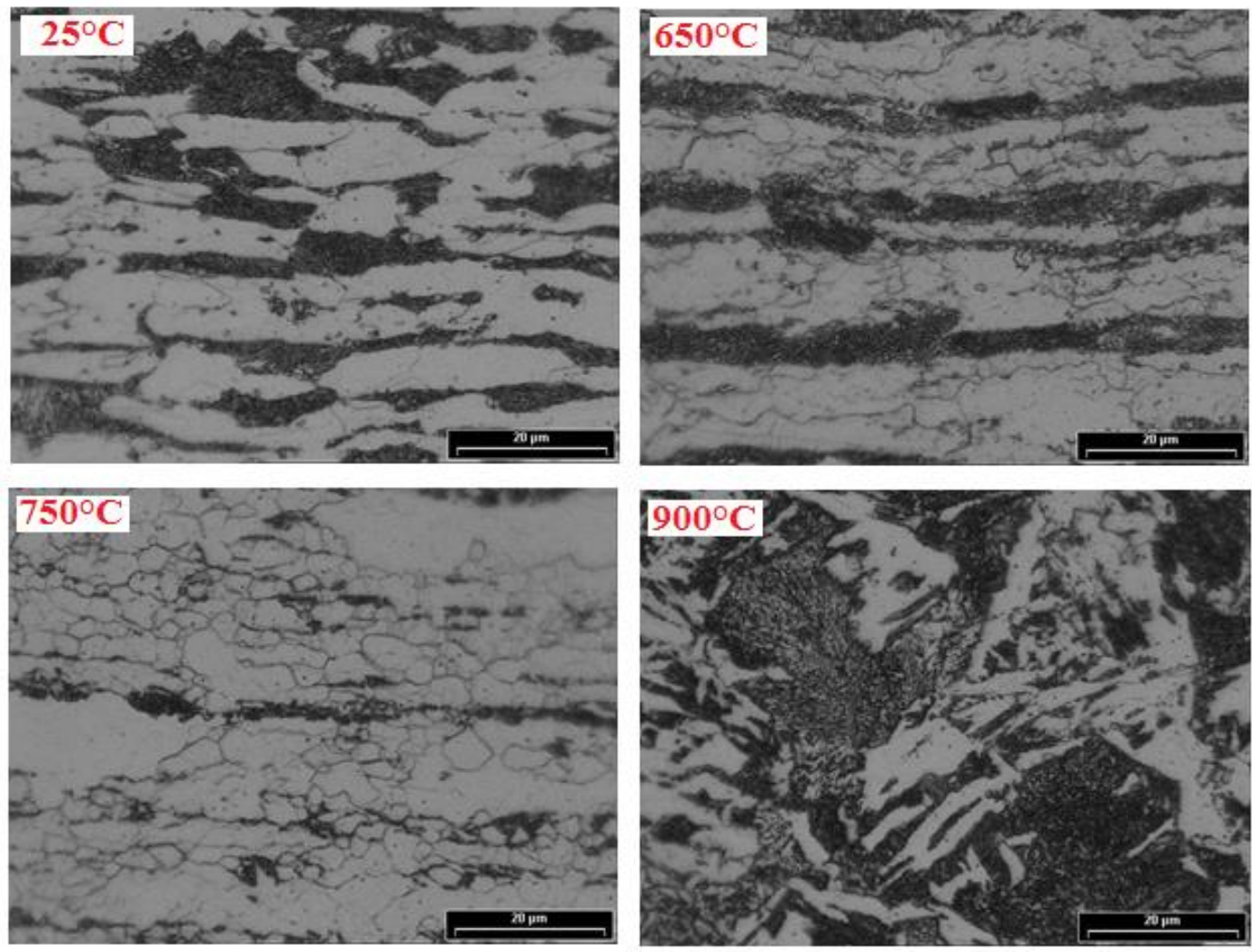

Figura 6. Microestrutura representativa para as temperaturas de $25^{\circ} \mathrm{C}, 650^{\circ} \mathrm{C}, 750^{\circ} \mathrm{C}$ e $900^{\circ} \mathrm{C}$. Aumento 1000X. Ataque Nital 3\%.

\subsection{RESULTADOS EXPERIMENTAIS E MODELOS CONSTITUTIVOS}

As curvas tensão-deformação foram ajustadas pela aplicação de duas relações constitutivas diferentes. Na primeira abordagem, o modelo de Voce foi aplicado em combinação com o modelo cinético de Kocks. Todos os parâmetros usados nos modelos foram retirados do artigo Naderi (2008a), onde as mesmas relações constitutivas foram utilizadas para obtenção das curvas tensão vs. deformação verdadeira do aço 22MnB5 deformado isotermicamente por compressão.

Em seu estudo, Naderi (2008a) utilizou a relação de Voce - Kocks para obter a curva tensão vs deformação do aço $22 \mathrm{MnB} 5$ para diferentes temperaturas e taxas de deformação através do ensaio de compressão, sendo que após a austenitização, os corpos de prova eram resfriados a uma taxa de $50^{\circ} \mathrm{C} / \mathrm{seg}$ até a temperatura de ensaio, o que não ocorreu nos ensaios realizados nesse estudo onde os corpos de prova foram resfriados a taxas superiores, $6,97^{\circ} \mathrm{C} / \mathrm{min}$. Os resultados do autor mostraram que para as condições de ensaio utilizadas, o modelo de Voce - Kocks se ajusta as curvas experimentais obtidas para as temperaturas e taxas de deformação utilizadas no experimento. 
Na segunda abordagem, a equação de Hollomon foi utilizada para que os resultados pudessem ser comparados com os obtidos no modelo de Voce - Kocks. Utilizando como referência os valores experimentais, foi feito o ajuste desses resultados às equações de Voce e Hollomon. As equações de lei de potência propostas por Hollomon puderam ajustar as curvas tensão vs. deformação em que a tensão aumenta monotonicamente, enquanto a equação de Voce é adequada quando a tensão satura em grandes deformações.

Através de regressão pelo método dos mínimos quadrados não lineares, às curvas obtidas pelo modelo de Voce-Kocks e pela eq. de Hollomon foram ajustadas aos dados experimentais e depois extrapoladas para maiores deformações. A Figura 7 mostra o comparativo entre os resultados experimentais e os resultados obtidos com os modelos constitutivos, e suas extrapolações.

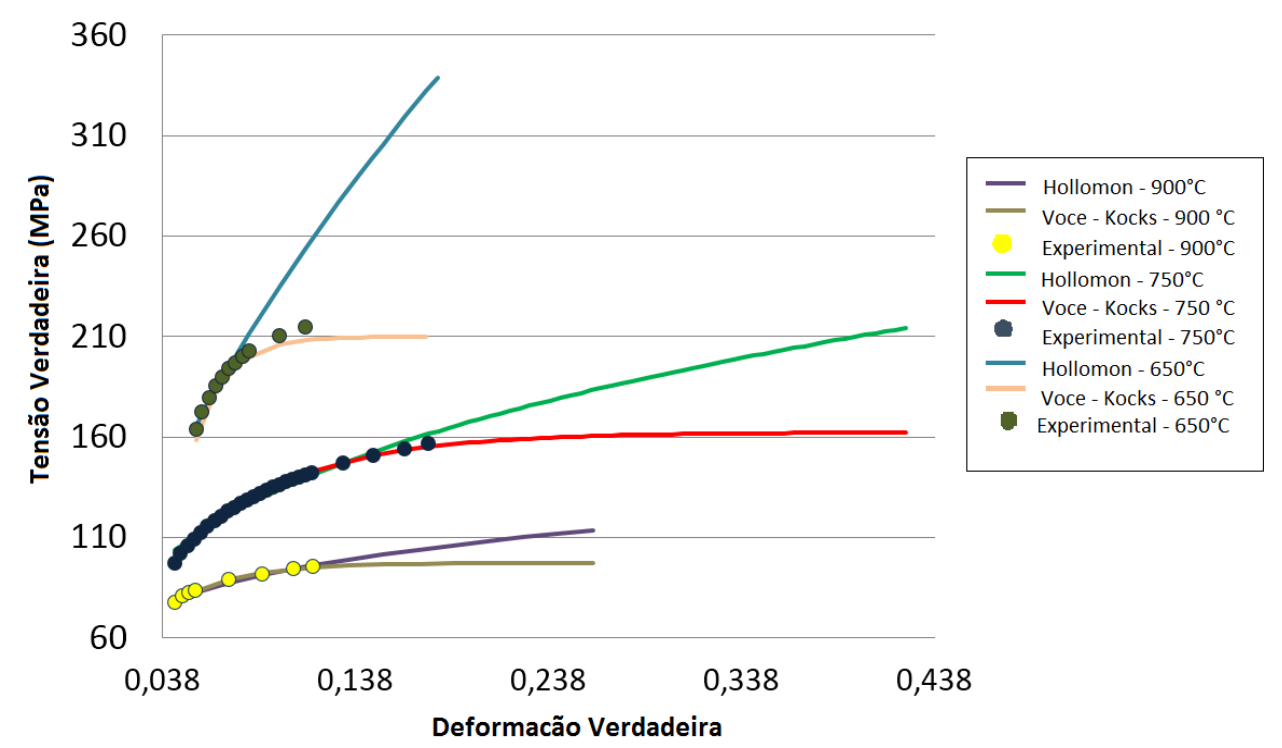

Figura 7. Comparativo entre os resultados experimentais e os resultados obtidos com os modelos constitutivos, e suas extrapolações.

Nas curvas dos CPs ensaiados a $900^{\circ} \mathrm{C}$, pode-se observar que a parte que coincide com os pontos experimentais não representa o comportamento mecânico do material como um todo, conforme a Figura 8. Pode-se dizer que os dois modelos se ajustam aos dados experimentais, sendo o modelo de Voce - Kocks mais aderente. A diferença entre as curvas características de cada modelo é acentuada somente após deformação bem mais significativa do que a apresentada pelos corpos de prova antes da estricção.

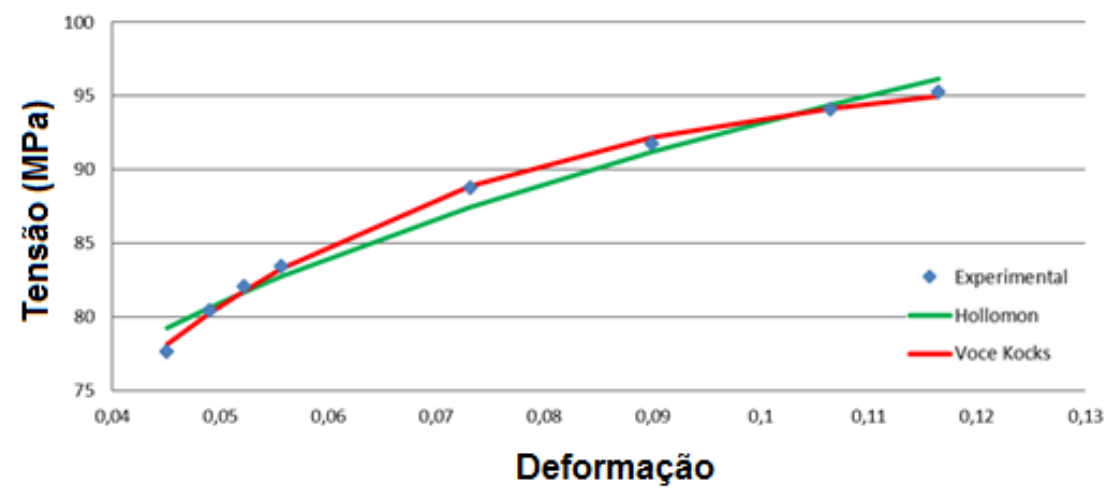


Figura 8. Curvas tensão vs deformação verdadeiras experimentais e modeladas representativas para os CPs ensaiados a $900^{\circ} \mathrm{C}$.

Nas curvas dos $\mathrm{CPs}$ ensaiados a $750^{\circ} \mathrm{C}$, pode-se observar que os últimos pontos experimentais coincidiram com a curva do modelo de Voce - Kocks após a separação das curvas dos dois modelos, conforme Figura 9. Isso foi um indicativo de que caso o ensaio continuasse os pontos experimentais se ajustariam à curva de Voce - Kocks. Notou-se que a diminuição da temperatura permitiu um maior alongamento antes do início da estricção, o que possibilitou a observação do comportamento experimental do material em pontos além daqueles alcançados nos corpos de prova ensaiados a $900^{\circ} \mathrm{C}$.

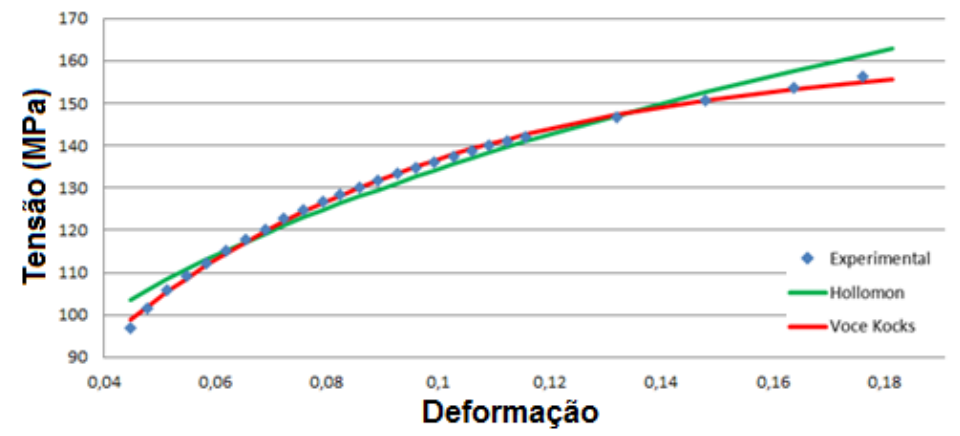

Figura 9. Curvas tensão vs deformação verdadeiras experimentais e modeladas representativas para os CPs ensaiados a $750^{\circ} \mathrm{C}$.

Nas curvas dos $\mathrm{CPs}$ ensaiados a $650^{\circ} \mathrm{C}$, pode-se observar que os últimos pontos experimentais coincidiram com a curva do modelo de Voce - Kocks após a separação das curvas dos dois modelos, assim como nos corpos de prova ensaiados a $750^{\circ} \mathrm{C}$, corroborando que, caso o ensaio continuasse, os pontos experimentais se ajustariam à curva de Voce-Kocks, conforme ilustra a Figura 10. Também foi possível observar o aumento no alongamento, fazendo com que os últimos pontos experimentais estejam bem próximos a tensão de saturação do modelo de Voce - Kocks.

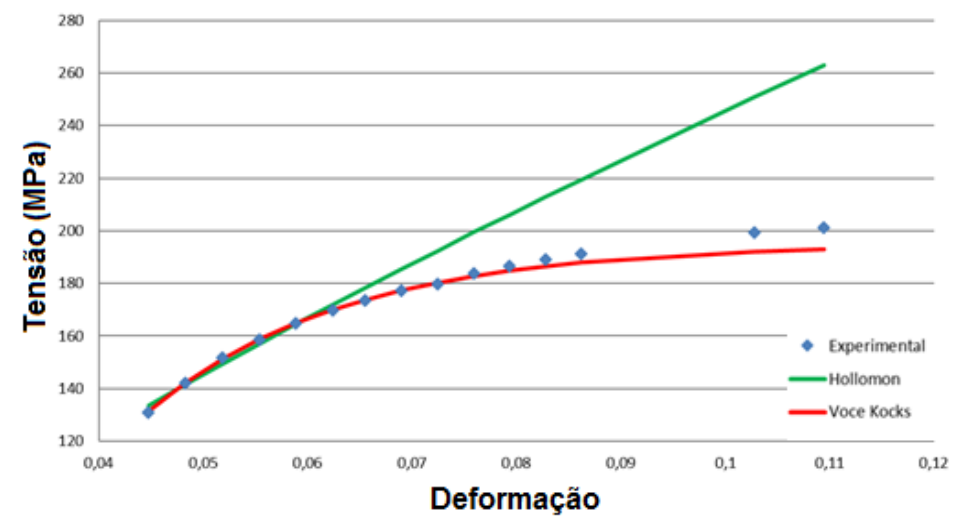

Figura 10. Curvas tensão vs deformação verdadeiras experimentais e modeladas representativas para os CPs ensaiados a $650^{\circ} \mathrm{C}$.

Ao serem comparados os resultados para as três temperaturas ensaiadas, percebeu-se que quanto mais tarde ocorre a redução de área, mais os pontos experimentais coincidem com o modelo de Voce-Kocks. Quando a estricção ocorre para alongamentos muito inferiores, como no caso dos corpos de prova ensaiados a 
$900^{\circ} \mathrm{C}$, o modelo de Voce - Kocks e a equação de Hollomon apresentam valores similares e ajustes aceitáveis para os pontos experimentais.

\section{CONCLUSÃO}

O sistema de aquecimento resistivo desenvolvido para a obtenção de propriedades mecânicas em altas temperaturas foi capaz de entregar resultados com a devida repetibilidade, para as três temperaturas analisadas neste trabalho.

A temperatura exerceu forte influência sobre as propriedades mecânicas finais do aço $22 \mathrm{MnB5}$ e em seu comportamento durante a deformação. As microestruturas obtidas nos corpos de prova ensaiados a 650 e $750^{\circ} \mathrm{C}$ são características de materiais que sofreram resfriamento lento dentro do forno, enquanto a microestrutura dos corpos de prova ensaiados a $900^{\circ} \mathrm{C}$ e resfriados ao ar apresentaram fases decorrentes de processos não difusionais (como ferrita acicular e bainita). Descrição das principais conclusões.

O modelo de Voce-Kocks demonstrou ajuste satisfatório nos casos em que o alongamento antes da estricção atingiu valores onde sua curva se separa da Eq. Hollomon e permitiu evidenciar seu melhor ajuste aos resultados experimentais. Para a geometria do corpo de prova utilizado, a redução de área não permitiu a avaliação plena do comportamento mecânico do material, visto que a redução da área iniciou-se para tensões relativamente baixas quando comparadas à tensão de saturação do modelo de Voce - Kocks.

Para melhor avaliação e aproveitamento dos resultados dos ensaios, sugere-se a maior capacidade de redução de área dos corpos de prova, conforme ocorreu nos corpos de prova ensaiados a temperaturas mais baixas. Como a temperatura é a principal variável a ser estudada e não pode ser reduzida, recomenda-se aumentar a área útil do corpo de prova e a utilização de corpo de prova de seção circular sempre quando possível.

\section{Agradecimentos}

Ao Centro de Pesquisas, Desenvolvimento e Inovação da Companhia Siderúrgica Nacional onde esse trabalho foi realizado.

\section{REFERÊNCIAS}

1 GORNI, A. A. e outros. O efeito do boro na resistência à deformação a quente de aços com baixo carbono. In: $42^{\circ}$ Seminário de Laminação - Processos e Produtos Laminados e Revestidos, Associação Brasileira de Metalurgia e Materiais - ABM, Santos (SP), 25 a 28 de Outubro de 2005.

2 NADERI, M. Hot Stamping of Ultra High Strength Steels. PhD thesis Master of Science, Iran, November 2007.

3 NADERI, M. SAEED-AKBARI, A. BLECK, W. The effects of non-isothermal deformation on martensitic transformation in $22 \mathrm{MnB5}$ steel. Materials Science and Engineering, $A$ 487 pag. 445-455. (2008)

4 ALTAN, T. Hot-stamping boron-alloyed steels for automotive parts. Part I: Process methods and uses. Stamping Journal. (2006)

5 FERRER, M. H., Estudo das transformações de fase de aço TRIP ao Si-Mn microligados com Nb, Tese de Doutorado em engenharia, Escola Politécnica da USP, São Paulo, SP, maio 2003.

6 NADERI, M.; BLECK, W. WIT Trans. Eng. Sci. 57 pag. 95-104. (2007) 
7 NADERI, M.; SAEED-A, A. Mater. Sci. Eng. A 487 pag.445-455. (2008)

8 NADERI, M.; DURRENBERGER, L.; MOLINARI, A.; BLECK, W. Constitutive relationships for 22MnB5 boron steel deformed isothermally at high temperatures. Mater Sci Eng, A, 478, pag. 130-139. (2008)

9 FRÖBERG, C. E. Introduction to Numerical Analysis Addison-Wesley, 1965.

10 HOLLOMON J.H. Trans. AIME, 162 (1945), pp. 268-290 